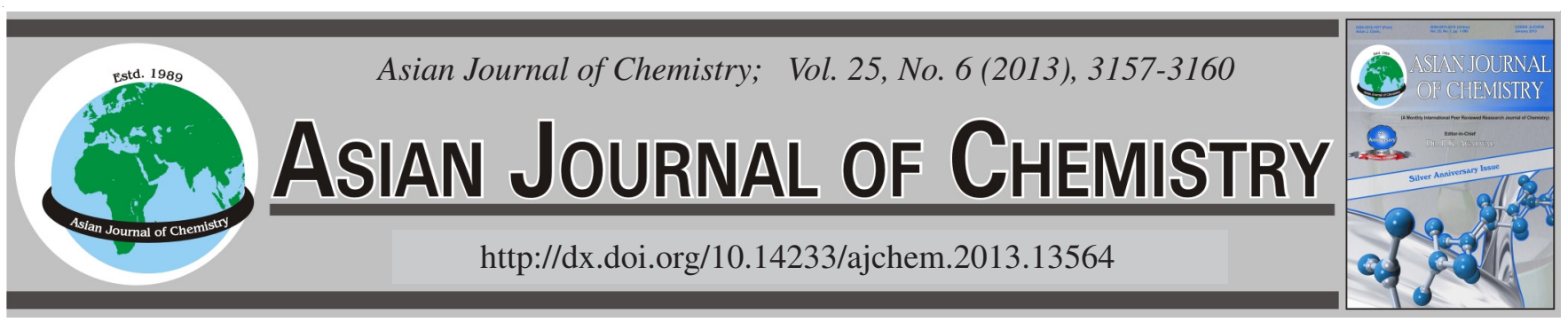

\title{
Simultaneous Determination of Thiamine and Pyridoxine in Bulk Drug and Vitamin Tablet by HPLC-UV Method
}

\author{
Onur Senol and Yucel Kadioglu*
}

Department of Analytical Chemistry, Faculty of Pharmacy, Ataturk University, 25240 Erzurum, Turkey

*Corresponding author: Fax: +90 442 2360962; Tel: +90 442 2315212; E-mail: yucel@atauni.edu.tr; yucelkadi@yahoo.com

Thiamine and pyridoxine which are also called vitamin $\mathrm{B}_{1}$ and $\mathrm{B}_{6}$, play crucial role in biochemical reactions in human body. HPLC-UV method for the quantitative determination of thiamine and pyridoxine in bulk drug and vitamin tablet were developed and validated in the present study. The mobile phase consisted of a mixture of water $(\mathrm{pH}: 3.5)$ and methanol $(91: 9, \mathrm{v} / \mathrm{v})$ flowing at a flow rate of $1.0 \mathrm{~mL} / \mathrm{min}$. Calibration curve was linear between concentration range of $1-40 \mu \mathrm{g} / \mathrm{mL}$. The intraday and interday precision and accuracy were between 0.8-5.4\% and 0.2-6.6\% for both analytes, respectively. Besides, the method was successfully applied to the simultaneous determination of thiamine and pyridoxine in vitamin tablet.

Key Words: Thiamine, Pyridoxine, HPLC-UV method, Vitamin tablet.

L - - - - - - - - - - - - - - - - - - - - - - - - - - - - - -

\section{INTRODUCTION}

Vitamin B complexes are water soluble molecules. They play an important role on many biochemical reactions in human body such as carbohydrate synthesis, enzymatic cofactor glycosis ${ }^{1}$. Thiamine ( $\mathrm{B}_{1}$ : 3-(4-amino-2-methyl-pyrimidyl-5methyl)-4-methyl-( $\beta$-hydroxyethyl)-thiazole, Fig. 1 A) and pyridoxine ( $\mathrm{B}_{6}$ : 2-methyl-3-hydroxy-4,5-bis-(hydroxy-methyl) pyridine, Fig. 1 B) are the members of the vitamin B groups. Active form of thiamine is found in human body as thiamine diphosphate. Other phosphorilated forms are thiamine monophosphate and thiamine poly phosphate ${ }^{2}$. However, their mechanisms are not completely explained and because of that reason determination of thiamine and its metabolytes are quite important and it is a main interest for many scientists. Insufficient intake mostly causes severe disease, such as beriberi, malaise, weight lose, irritability and confusion ${ }^{3}$.

Three different natural forms (vitamers) of vitamin $\mathrm{B}_{6}$ is reported, namely pyridoxine, pyridoxamine and pyridoxal, all of which are normally present in foods ${ }^{4}$. Pyridoxal 5' -phosphate (PLP), pyridoxic acid, pyrdoxamine 5-phosphate and pyridoxine 5-phosphate are metabolytes of pyridoxine vitamin. Deficiency of pyridoxine leads to seborrhoeic dermatitis, atrophic glossitis with ulceration, angular cheilitis, confusion and neuropathy in human body ${ }^{4}$.

The literature shows that spectrophotometric method ${ }^{5-10}$, wavelet transform ${ }^{11,12}$, spectrofluorimetric method ${ }^{13,14}$ and potentiometric method ${ }^{15,16}$ have been reported for determination of the binary mixture of thiamine and pyridoxine with other vitamins pharmaceutical preparations. Besides, the determinations of thiamine and pyridoxine together with different compounds have been done with HPLC method with different detections ${ }^{17-27}$.<smiles></smiles>

A)

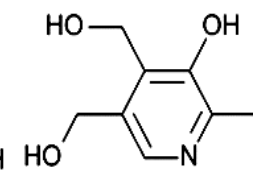

B)
Fig. 1. Chemical structure of thiamine (A) and pyridoxine (B)

The aim of this study was to optimize an HPLC-UV method for simulations determination of thiamine and pyridoxine in vitamin tablet. The influence of operating conditions on the resolution of both analytes was examined and good resolution conditions were identified. The validation of method was carried out by establishing specifity, linearity, stability, analytical recovery, limit of detection, limit of quantitation, precision and accuracy according to International Conference on Harmonization guidelines (ICH) for validation of analytical procedures $^{28}$.

\section{EXPERIMENTAL}

Standard pyridoxine (PY) and thiamine $(\mathrm{TH})$ reagents are purchased from Sigma (USA). Milli-Q pure water is used in 
all of the analysis where deionized water is required. HPLC grade methanol and analytical grade $\mathrm{HCl}$ are received from Merck (Germany).

The following vitamin tablet obtained from local sources in Erzurum (Turkey) was subjected to the described analytical procedures: Benol ${ }^{\circledR}$ Tablet (Aksu Pharma Ilac San.A.S., Turkey) containing pyridoxine and thiamine $250 \mathrm{mg} /$ tablet.

Chromatographic analysis was carried out on an Agilent 1200 series HPLC system, consisting of a degasser, quaternary pump, autosampler and variable wavelength UV detector units. The reversed-phase $\mathrm{ACE}_{18}$ analytical column $(250 \mathrm{~mm} \times$ $4.6 \mathrm{~mm}$ I.D., $5 \mu \mathrm{m}$ ) was used in chromatographic separation. The column and the HPLC system were kept at $25^{\circ} \mathrm{C}$ temperature. The mobile phase was a mixture of water ( $\mathrm{pH}: 3.5)$ methanol $(91: 9, \mathrm{v} / \mathrm{v})$ prepared and the injection volume was $10 \mu \mathrm{L}$.

Composition and flow rate of the mobile phase was programmed from mother pump and the mobile phase [water $(\mathrm{pH}: 3.5)$-methanol $(91: 9, \mathrm{v} / \mathrm{v})]$ was passed through the same. The mobile phase filtered through $0.22 \mu \mathrm{m}$ membrane filter using Millipore HPLC solvent filtration assembly, was delivered at $1.0 \mathrm{~mL} / \mathrm{min}$ for column stabilization, with continuous baseline monitoring. The wavelength of detection was fixed excitation at $274 \mathrm{~nm}$ and peak areas were integrated using Agilent ChemStation software program. The HPLC chromatograms of standard solutions of both analytes were given in Fig. 2 A-B.

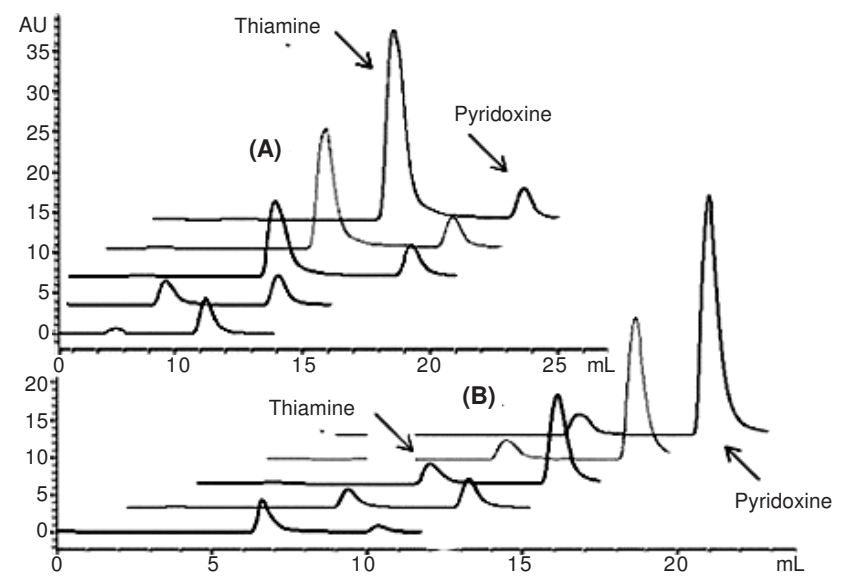

Fig. 2. HPLC chromatograms: A) standard solutions of thiamine including $5 \mu \mathrm{g} / \mathrm{mL}$ pyridoxine and B) standard solutions of pyridoxine including $5 \mu \mathrm{g} / \mathrm{mL}$ thiamine

Preparations of standard samples: The stock solutions $(100 \mu \mathrm{g} / \mathrm{mL})$ of pure drugs (pyridoxine and thiamine) were prepared by dissolving of $10 \mathrm{mg}$ of both compounds in 100 $\mathrm{mL}$ of deionized water including $0.1 \mathrm{M} \mathrm{HCl}$. From this stock solutions, the working standard (WS) solutions at 1, 5, 15, 25 and $40 \mu \mathrm{g} / \mathrm{mL}$ concentrations of both compounds were prepared by suitable dilution in $10 \mathrm{~mL}$ volumetric flask. The quality control (QC) solutions $(2.5,10$ and $30 \mathrm{mg} / \mathrm{mL})$ were prepared in a similar manner. The quality control samples were used to assess the accuracy and precision of the assay method.

Pharmaceutical preparation: Eight tablets of Benol ${ }^{\circledR}$ tablet were carefully weighed and ground to finely powders. Accurate weights equivalent to weight of one tablet was dissolved in $100 \mathrm{~mL}$ water including $0.1 \mathrm{M} \mathrm{HCl}$. Solutions were stand for about $5 \mathrm{~min}$ and filtered up using $12 \mathrm{~mm}$ filter paper. The filtrate was diluted with water $(0.1 \mathrm{M} \mathrm{HCl})$ to obtained $5 \mu \mathrm{g} / \mathrm{mL}$ concentration of both compounds for tablet.

\section{RESULTS AND DISCUSSION}

Optimization of HPLC conditions: To obtain accurate, valid and optimal chromatographic conditions, different HPLC parameters were examined and compared, including the various ratio of water and methanol of mobile phase, various $\mathrm{pH}(2.5,3.0$ and 3.5$)$ of mobile phase, column temperatures $\left(20,25\right.$ and $\left.30^{\circ} \mathrm{C}\right)$ and mobile phase flow rates (1.0, 1.5 and $2.0 \mathrm{~mL} / \mathrm{min}$ ). The resolution of peaks and analysis time are important for every study. In this study, the followed resolution equation was used:

$$
\mathrm{R}_{\mathrm{S}}=\frac{2(\mathrm{tj}-\mathrm{ti})}{(w j+w i)}
$$

where $t j$ and ti are the retention time of pyridoxine and thiamine and wj and wi are the peak widths of the peaks of both compounds, peak $\mathrm{i}$ being the first and peak $\mathrm{j}$ being the next.

In the search of an appropriate mobile phase, it was tried to change the ratio of water and methanol as 70:30, 80:20 and 91/9 (v/v) and also pH (2.5, 3.0 and 3.5) of mobile phase. It was observed that neutral mobile phases produced low sensitivity as compared with acidic mobile phases. The symmetrical peaks were obtained in $\mathrm{pH} 3.5$ but no symmetrical peak was observed in $\mathrm{pH} 2.5$ and $\mathrm{pH}$ 3.0. Mobil phase 91/9 (water/ methanol, v/v) produced well resolved definite peaks (Rs > 1.5) (Fig. 3). Therefore, the mobile phase [water ( $\mathrm{pH}: 3.5)$ - methanol (91:9, v/v)] was used as optimum solvent system for next steps of our study. Similarly, various column temperatures $\left(20,25\right.$ and $\left.30^{\circ} \mathrm{C}\right)$ and mobile phase flow rates (1.0, 1.5 and $2.0 \mathrm{~mL} / \mathrm{min}$ ) were also tried and separation was optimum at $25^{\circ} \mathrm{C}$ as column temperature and $1.0 \mathrm{~mL} / \mathrm{min}$ as flow rates so it was used for next steps of study.

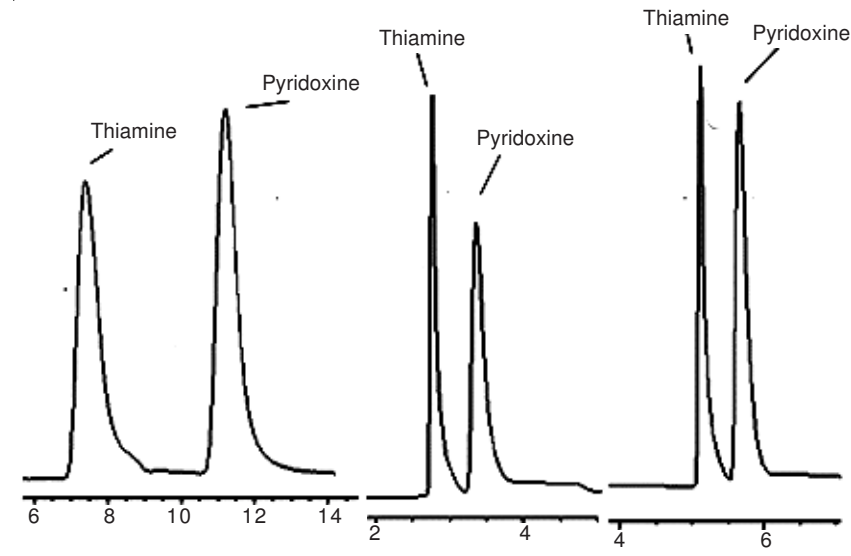

(A)

(B)

(C)

Fig. 3. Effect of composition of mobile phase (water-methanol, v/v): A) 91:9; B) $70: 30$ and C) $80: 20$

Linearity: Linearity signs the correlation between concentration and peak area. No correlation numbered as 0 and the highest correlation numbered as 1 . It means that closeness to 1 value is an evidence for high correlation between concentration 
and peak area. Linearity was evaluated using freshly prepared standard samples in the concentration range of $1-40 \mu \mathrm{g} / \mathrm{mL}$. Peak areas were plotted against thiamine or pyridoxine concentrations and standard curves were calculated by the equation: $\mathrm{y}=\mathrm{mx}+\mathrm{c}$ using weighted $\left(1 /\right.$ response $\left.^{2}\right)$ least square regression. A correlation of more than 0.99 was desirable for calibration curves of both analytes. The regression equations were calculated from the calibration graphs, along with the standard deviations of the slope and intercept on the ordinate. The obtained data were given in Table-1.

TABLE-1

RESULTS OF REGRESSION ANALYSIS OF THIAMINE AND PYRIDOXINE BY PROPOSED METHOD $(\mathrm{n}=6)$

\begin{tabular}{cccccc}
\hline Analyte & $\begin{array}{c}\text { Range } \\
(\mu \mathrm{g} / \mathrm{mL})\end{array}$ & LRE & Sa & Sb & $\mathrm{R}$ \\
\hline TH & $1-40$ & $\mathrm{y}=30.25 \mathrm{x}-4.634$ & 0.155 & 1.364 & 0.9982 \\
PY & $1-40$ & $\mathrm{y}=30.09 \mathrm{x}-6.035$ & 0.531 & 2.169 & 0.9984
\end{tabular}

LRE: linear regression equation, R: Coefficient of correlation, $y$ : Peakarea, $\mathrm{x}$ : concentration of both analytes; Sa:Standard deviation of slope, Sb:Standard deviation of intercept

Accuracy and precision: Accuracy is a parameter for correctness of a single measurement and precision is defined as the reproducibility of multiple measurements for the method. These two parameters are taken into account by taking three different quality control samples $(2.5,10$ and $30 \mu \mathrm{g} / \mathrm{mL})$ and making intra-day and inter-day assays for pyridoxine and thiamine. The precision of the method was reported as the relative standard deviation (RSD \%=100 x standard deviation/ mean) and the accuracy of the method was given with percent relative error $(\mathrm{RE})[\mathrm{RE}=$ (concentration found-known concentration $) \times 100 /$ known concentration]. The $\mathrm{RSD} \%$ values $(\mathrm{n}=$ 6 ) for intra-day and inter-day precision for the proposed method were $\leq 4.5 \%$ (for thiamine) and $\leq 5.4 \%$ (for pyridoxine). The RE $\%$ values $(n=6)$ for the intraday and interday accuracy studies of method were $\leq 6.6 \%$ (for thiamine) and $\leq 3.6 \%$ (for pyridoxine). Precision and accuracy studies in human plasma showed acceptable RSD \% and RE \% values. The results were shown in Table-2.

Sensitivity: The limit of detection (LOD) is the lowest amount of analyte in a sample which can be detected but not necessarily quantitated as an exact value. The limit of quantitation (LOQ) is the lowest amount of analyte which can be quantitatively determined with suitable precision. In order to find LOD and LOQ values, different concentrations of thiamine and pyridoxine which were lower than $1 \mu \mathrm{g} / \mathrm{mL}$ were prepared. According to chromatograms, LOD that was defined as signal/-noise $=3$ was found to be $0.5 \mu \mathrm{g} / \mathrm{mL}$ for both analytes. LOQ that was defined signal $/$ noise $=8$, for thiamine and pyridoxine were found to be $1.0 \mu \mathrm{g} / \mathrm{mL}$. Both accuracy and precision of these values were well within the proposed criteria ( $\mathrm{RSD} \%<20 \%$ ).

Analytical Recovery: To double check the accuracy of the proposed method, the standard addition technique was applied. The three different concentrations $(2.5,10$ and $30 \mu \mathrm{g} /$ $\mathrm{mL}$ ) of pure sample solutions for both analytes were added to $5 \mu \mathrm{g} / \mathrm{mL}$ concentration of solution of Benol ${ }^{\circledR}$ tablet and assayed with HPLC-UV method. The present analytical recovery of the added standard to the assay samples was calculated from followed equation:

Analytical recovery $\%=\left[\left(\mathrm{C}_{\mathrm{t}}-\mathrm{C}_{\mathrm{u}}\right) / \mathrm{C}_{\mathrm{a}}\right] \times 100$

where $C_{t}$ is total concentration of the analyte determined; $C_{u}$ is the concentration of the pure analyte added to the formulation; $\mathrm{C}_{\mathrm{a}}$ is the concentration of the analyte present in the formulation. The average percent recoveries for thiamine and pyridoxine were quantitatively determined as $98.1 \%$ and $100.7 \%$ for proposed method, indicating good accuracy of the method. No interference from the common excipients was observed. The RSD \% values of recovery were found as ranged from $1.4 \%$ to $4.1 \%$ (Table-3).

Application of method for analysis of pharmaceutical preparation: The proposed method was evaluated in the assay

TABLE-2

PRECISION AND ACCURACY OF THE METHOD FOR DETERMINATION OF THIAMINE (TH) AND PYRIDOXINE (PY)

\begin{tabular}{|c|c|c|c|c|c|c|c|}
\hline \multirow{2}{*}{ Analyte } & \multirow{2}{*}{$\begin{array}{c}\text { Added } \\
(\mu \mathrm{g} / \mathrm{mL})\end{array}$} & \multicolumn{3}{|c|}{ Intra-day } & \multicolumn{3}{|c|}{ Inter-day } \\
\hline & & Found $\pm \mathrm{SD}$ & Precision RSD (\%) & Accuracy RE (\%) & Found \pm SD & Precision RSD (\%) & Accuracy RE (\%) \\
\hline \multirow{3}{*}{ Thiamine } & 2.5 & $2.39 \pm 0.08$ & 3.4 & -4.4 & $2.42 \pm 0.11$ & 4.5 & -3.2 \\
\hline & 10 & $9.70 \pm 0.12$ & 1.2 & -3.0 & $9.60 \pm 0.32$ & 3.3 & -4.0 \\
\hline & 30 & $28.74 \pm 0.31$ & 1.1 & -4.2 & $28.0 \pm 0.32$ & 1.1 & -6.6 \\
\hline \multirow{3}{*}{ Pyridoxine } & 2.5 & $2.48 \pm 0.09$ & 3.6 & -0.8 & $2.41 \pm 0.13$ & 5.4 & -3.6 \\
\hline & 10 & $10.09 \pm 0.34$ & 3.4 & 0.9 & $10.02 \pm 0.38$ & 3.8 & 0.2 \\
\hline & 30 & $30.07 \pm 0.36$ & 1.2 & -0.2 & $30.08 \pm 0.24$ & 0.8 & 0.3 \\
\hline
\end{tabular}

SD: Standard deviation of six replicate determinations, RSD: Relative standard deviation, RE: Relative error

TABLE-3

ANALYTICAL RECOVERY VALUES BY STANDARD ADDITION METHOD

\begin{tabular}{|c|c|c|c|c|c|}
\hline Analyte & $\begin{array}{c}\text { Amount taken } \\
(\mu \mathrm{g} / \mathrm{mL})\end{array}$ & $\begin{array}{c}\text { Amount added } \\
(\mu \mathrm{g} / \mathrm{mL})\end{array}$ & $\begin{array}{l}{ }^{\mathrm{a}} \text { Total amount found } \\
(\mu \mathrm{g} / \mathrm{mL})(\text { mean } \pm \mathrm{SD})\end{array}$ & $\begin{array}{c}\text { Recovery } \\
(\%)\end{array}$ & $\begin{array}{c}\mathrm{RSD} \\
(\%)\end{array}$ \\
\hline \multirow{3}{*}{ Thiamine } & \multirow{3}{*}{5.0} & 2.5 & $7.4 \pm 0.1$ & 98.0 & 1.4 \\
\hline & & 10 & $15.02 \pm 0.5$ & 100.4 & 3.3 \\
\hline & & 30 & $34.8 \pm 1.1$ & 96.0 & 3.2 \\
\hline \multirow{3}{*}{ Pyridoxine } & \multirow{3}{*}{5.0} & 2.5 & $7.6 \pm 0.2$ & 102.0 & 2.6 \\
\hline & & 10 & $14.8 \pm 0.6$ & 96.0 & 4.1 \\
\hline & & 30 & $35.2 \pm 1.5$ & 104.0 & 4.3 \\
\hline
\end{tabular}

${ }^{a}$ Average of six replicate determinations 
TABLE-4

DETERMINATION BY PROPOSED METHOD OF $250 \mathrm{mg}$ PYRIDOXINE + $250 \mathrm{mg}$ THIAMINE IN TABLET

\begin{tabular}{|c|c|c|c|c|c|c|}
\hline Tablet & $\lambda(\mathrm{nm})$ & Analyte & ${ }^{\mathrm{a}}$ Found $\pm \mathrm{SD}(\mathrm{mg})$ & Recovery (\%) & RSD (\%) & Confidence interval \\
\hline \multirow{2}{*}{ Benol $^{\circledR}$ tablet } & \multirow{2}{*}{$274 \mathrm{~nm}$} & PY & $249.6 \pm 8.1$ & 99.8 & 3.25 & $94.92-105.3$ \\
\hline & & $\mathrm{TH}$ & $250.8 \pm 4.7$ & 100.3 & 1.87 & $98.09-102.0$ \\
\hline
\end{tabular}

of commercially available tablet containing $250 \mathrm{mg}$ thiamine and $250 \mathrm{mg}$ pyridoxine (Benol ${ }^{\circledR}$ tablet). Evaluation was performed using the calibration curve method since no significant difference between the slopes of the calibration curves for standards and pharmaceutical preparation solution was observed. The amount of tablet $250 \mathrm{mg}$ thiamine and $250 \mathrm{mg}$ pyridoxine was determined by six replicates. The obtained results are satisfactorily accurate and precise as indicated by the excellent $\%$ recovery and SD $<8.1$ and 4.7 (Table-4). Experiments showed that there was no interference from the additives or excipients (Fig. 4). The determination repeated for six times, final recovery of formulations was obtained approximately to be $99.8 \%$ (for pyridoxine) and $100.3 \%$ (for thiamine), with an RSD \% of $3.25 \%$ and $1.87 \%$, respectively.

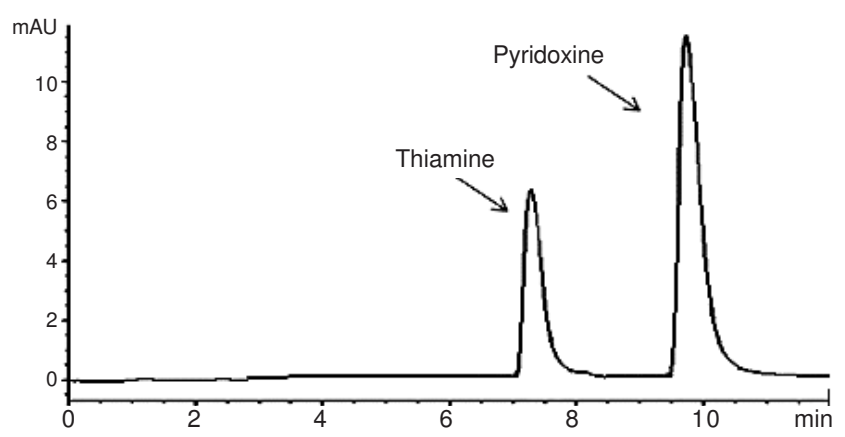

Fig. 4. Chromatogram of solution $(5 \mu \mathrm{g} / \mathrm{mL})$ of Benol(R) tablet

Many HPLC studies have been reported for the determination of thiamine and pyridoxine in pharmaceutical preparation. In these studies, thiamine and pyridoxine have determined together with different compounds, such as niacin, niacinamide, riboflavin, cyanocobalamin, calcium folinate, ascorbic acid, caffeine, codeine, paracetamol, folic acid, pyridoxal, by HPLC method with different detection in multivitamin tablets ${ }^{17-28}$. In the present study, a highly selective HPLC method based separation combined a UV detection that enabled us to quantify the pyridoxine and thiamine without derivatization in vitamin tablet was developed and validated. The proposed method has supplied all the requirements in terms of accuracy, linearity, recovery and precision that could be accepted as a reliable and applicable method. The precision of method for both analytes was adequate, because the RSD \% values were less than $5.4 \%$, accuracy of method (RE \%) was less than $6.6 \%$. There are several advantages of this method which are high specificity, high analytical recovery, good accuracy and precision values. In the taken chromatograms, the retention time of thiamine and pyridoxine were approx. $7.5 \mathrm{~min}$ and $11.5 \mathrm{~min}$, respectively. Under the described chromatographic conditions a linear relationship between the peak area (y) and analyte concentration $(\mathrm{x})$ for both analytes were obtained (Table-1).

\section{Conclusion}

HPLC-UV method for determination of thiamine and pyridoxine without derivatization in vitamin tablet were developed and completely validated by using sensitivity, specificity, linearity, accuracy and precision parameters. The proposed methods have high recovery and excellent reproducibility.

\section{REFERENCES}

1. T. Perez-Ruiz, C. Martinez-Lozano, A. Sanz and A. Guillen, J. Pharm. Biomed. Anal., 34, 551 (2004).

2. R. Losa, M.I. Sierra, A. Fernandez, D. Blanco and J.M. Buesa, J. Pharm. Biomed. Anal., 37, 1025 (2005).

3. P.L.M. Lynch and I.S. Young, J. Chromatogr. A., 881, 267 (2000).

4. Monograph, Alternat. Med. Rev., 6, 87 (2001).

5. D. Ozdemir and E. Dinc, Chem. Pharm. Bull., 52, 810 (2004).

6. P.O. Barrales, A.D. Vidal, M.L.F. de Cordova and A.M. Diaz, J. Pharm. Biomed. Anal., 25, 619 (2001).

7. Y.H. Chen, J.F. Zhang, F.S. Tian and Y.H. Zhang, Asian J. Chem., 23, 2169 (2011).

8. F.R.P. Rocha, F.O. Fatibello and B.F. Reis, Talanta, 59, 191 (2000).

9. E. Dinc, G. Kokdil and F. Onur, J. Pharm. Biomed. Anal., 22, 915 (2000).

10. V. Such, J. Traveset, R. Gonzalo and E. Gelpi, Anal. Chem., 52, 412 (1980).

11. E. Dinc and D. Baleanu, J. Pharm. Biomed. Anal., 31, 969 (2003).

12. E. Dinc and D. Baleanu, Talanta, 59, 707 (2003).

13. M. Barary, M. Abdel-Hamid, E. Hassan and M. Elsayed, Pharmazie, 41, 483 (1986).

14. L. Garcia, S. Blazquez, M.P. San Andres and S. Vera, Anal. Chim. Acta, 434, 193 (2001).

15. A.R. Pires, A.N. Araujo, J.A. Lopes, M. Conceiçao and B.S.M. Montenegro, Anal. Lett., 42, 1923 (2009).

16. S.A. Halvatzis and M. Timotheou-Potamia, Anal. Chim. Acta, 227, 405 (1989).

17. R.L. Kirchmeier and R.P. Upton, J. Pharm. Sci., 67, 1444 (1978).

18. T. Cannella and G. Bichi, Boll. Chim. Farm., 122, 205 (1983).

19. F.L. Lam, I.J. Holcomb, S.A. Fusari, J. AOAC Int., 67, 1007 (1984).

20. N. Ramos-Martos, F. Aguirre-Gomez, A. Molina-Diaz and L.F. CapitanVallvey, J. AOAC Int., 84, 676 (2001).

21. M.L. Marszall, A. Lebiedzinska, W. Czarnowski and P. Szefer, J. Chromatogr. A, 1094, 91 (2005).

22. K. Li, Biomed. Chromatogr., 16, 504 (2002).

23. N. Yantih, D. Widowati and W. Tiwiaryani, Can. J. Sci. Ind. Res., 2, 269 (2011).

24. R. Admidzic, J. Brboric, O. Cudina and S. Vladimirov, J. Serb. Chem. Soc., 70, 1229 (2005).

25. O. Hassan and M.J. Chee, Malay. J. Anal. Sci., 7, 251 (2001).

26. K. Swan-Choo and T.E.-Siong., Malays. J. Nut., 2, 49 (1996).

27. C.K. Markopoulou, K.A. Kagkadis and J.E. Koundourellis, J. Pharm. Biomed. Anal., 30, 1403 (2002).

28. Validation of Analytical Procedures, Proceedings of the International Conference on Harmonization (ICH). Commission of the European Communities, (1996). 